gas chromatography-mass spectrometry. Application to the in vivo measurement of phenylalanine-4-monooxygenase activity. Journal of Chromatography, 142, 523-531.

J. Schaub*, S. Däumling*, H-Ch. Curtius $\dagger$, A. Niederwieser $\dagger$, K. Bartholomé $\S$, M. VisCONTINI + , B. SCHIRCKS + , AND J. H. BIERI

*Children's Hospital, University of Munich, Lindwurmstr. 4, D-8000 Munich, W. Germany; †Children's Hospital, University of Zurich, Switzerland; $\S$ Children's Hospital, University of Heidelberg, $W$. Germany; $\ddagger$ Chemical Institute, University of Zurich, Switzerland

Correspondence to Dr J. Schaub.

\section{Diagnosis of phaeochromocytoma after ingestion of imipramine}

We describe a case of phaeochromocytoma of the adrenal medulla in one of identical twin girls, diagnosed after the ingestion of imipramine.

\section{Case report}

An 11-year-old girl was admitted to hospital with a history of pallor and profuse sweating for 24 hours after a single dose of imipramine syrup (Tofranil $50 \mathrm{mg}$ ). There had been a similar episode 2 months earlier after medication with a tablet of imipramine $(50 \mathrm{mg})$. This drug had been prescribed by the family doctor for the treatment of nocturnal enuresis of a year's duration. After the first dose the girl had sweated profusely for about 12 hours. Her mother stopped her medicine but decided to reintroduce it 2 months later as bed-wetting had persisted. Within 6 hours the girl developed the symptoms which led to her admission.

On examination she was $6 \mathrm{~cm}$ shorter and $5 \mathrm{~kg}$ lighter than her twin, despite being slightly taller and heavier a year earlier. She was pale, cold, and drenched in sweat, with a temperature of $36 \cdot 2^{\circ} \mathrm{C}$. Her pupils were widely dilated but briskly reactive to light, and she had a pulse rate of $160 / \mathrm{min}$. Her blood pressure was $110 / 85 \mathrm{mmHg}$ and there were no other abnormal findings on physical examination. A random blood sugar was within normal limits and ECG showed sinus tachycardia.

By the next day her diastolic pressure had risen to $100 \mathrm{mmHg}$ and she continued in a state of sym- pathetic overactivity. A phaeochromocytoma was suspected.

Investigations included measurement of urinary hydroxy-methoxy-mandelic acid (HMMA) and metadrenaline levels. Both levels were raised at $30 \mu \mathrm{mol} / 24 \mathrm{~h}$ and $45.9 \mu \mathrm{mol} / 24 \mathrm{~h}$ respectively. Aortography confirmed the presence of a right-sided adrenal tumour. Her hypertension was controlled with oral phenoxybenzamine, and adrenalectomy was performed with full anaesthetic precautions (Crout and Brown, 1969). Histological examination of the tumour confirmed the diagnosis of phaeochromocytoma. After surgery her blood pressure returned to normal and there was no further enuresis. Urinary HMMA and metadrenaline levels fell to normal. The screening test for phaeochromocytoma was normal in her twin sister.

\section{Discussion}

Phaeochromocytoma is a rare condition and has been found once in a thousand necropsies in adults (Herman and Mornex, 1964). It is estimated that $0.5 \%$ of adult hypertensive patients in the USA have this tumour. For every 10 patients successfully treated, it is thought that there is one death from hypertensive crisis in a patient whose phaeochromocytoma is demonstrated at necropsy (Harrison, 1976). This tumour is considerably rarer in children (Wotherspoon et al., 1974), most reports being of single cases. Symptoms of the disease may be provoked by agents which stimulate release of amines, thereby producing abnormal pressor responses in the tumour. Such pressor agents may be used in provocative tests for the diagnosis of phaeochromocytoma, and include histamine, tetraethylammonium, and methacholine (Beeson and McDermott, 1971).

Imipramine is a tricyclic antidepressant which is commonly used to treat nocturnal enuresis in children. It possesses anticholinergic properties, and reported side effects include dryness of the mouth, dizziness, tachycardia, palpitations, and urinary retention. Excessive sweating has been reported although the mechanism is not known. Tricyclic antidepressants have also been shown to enhance the effects of catecholamines by blockade of active transport from extracellular fluid to cytoplasmic mobile pool (Axelrod et al., 1961).

Our patient may have had an idiosyncratic reaction to imipramine. This may have been the result of direct adrenal stimulation by the drug, or in response to excess catecholamine production after blockade in the re-uptake mechanism by imipramine. We are unaware of any previous report of phaeochromocytoma diagnosed after the ingestion of imipramine. 


\section{Summary}

An 11-year-old twin girl was admitted to hospital with a 24-hour history of profuse sweating, tachycardia, and hypertension after a single dose of imipramine. She was subsequently found to have a right adrenal phaeochromocytoma. To our knowledge, this is the first reported case of tumour provocation by imipramine.

We thank Dr H. Simpson for his permission to report this case.

\section{References}

Axelrod, J., Whitby, L. G., and Hertting, G. (1961). Effect of psychotropic drugs on the uptake of $\mathrm{H}^{3}$-norepinephrine by tissues. Science, 133, 383-384.

Beeson, P. B., and McDermott, W. C-L. (1971). Textbook of Medicine, thirteenth edition, pp. 1834-1836. Saunders: Philadelphia.

Crout, J. R., and Brown, B. R., Jr (1969). Anesthetic management of pheochromocytoma: the value of phenoxybenzamine and methoxyflurane. Anesthesiology, 30, 29-36.

Harrison, T. S. (1976). Pheochromocytoma-a hemicentennial. Johns Hopkins Medical Journal, 139, 137-144.

Herman, H., and Mornex, R. (1964). Human Tumours Secreting Catecholamines. Pergamon Press: New York.

Wotherspoon, G. P., Overton, J. H., and Lomaz, J. G. (1974). Phaeochromocytoma in a child. Anaesthesia and Intensive Care, 2, 83-86.

JACQUEline MoK AND IAN SwanN

The Royal Hospital for Sick Children, Sciennes Road, Edinburgh EH9 $1 L F$

Correspondence to Dr Jacqueline Mok.

\section{Sucrase-isomaltase deficiency}

\section{A follow-up report}

Sucrase-isomaltase deficiency is an autosomal recessive condition which usually presents in infancy with severe diarrhoea when sucrose is introduced into the diet. Sucrase deficiency was first described by Weijers et al. (1960); subsequently Anderson et al. (1962), using a qualitative method, reported deficiency of sucrase and isomaltase activities in duodenal biopsies of affected children. Burgess $e t$ al. (1964) reported 7 cases with quantitative estimations of mucosal disaccharidase activities. Four of these children were traced 10 years later and their progress is reported together with the progress of 5 children diagnosed more recently.

\section{Patients and methods}

All 9 children had presented with a typical history of chronic diarrhoea in infancy. In most cases this was severe and was associated with poor weight gain. The initial diagnosis of sucrase-isomaltase deficiency had been based on the following criteria. (1) A 'flat' sucrose tolerance test-i.e. after an oral sucrose load of $2 \mathrm{~g} / \mathrm{kg}$ the rise in blood glucose was $<20 \mathrm{mg} / 100 \mathrm{ml}(1 \cdot 1 \mathrm{mmol} / \mathrm{l})$. (2) A normal lactose and/or glucose tolerance test. (3) Histologically normal small intestinal biopsy. (4) Very low sucrase and palatinase activities while lactase was normal. Disaccharidases were measured by the method of Burgess et al. (1964). Palatinose was used as the substrate instead of isomaltose, as it is also hydrolysed by isomaltase.

In Case 9, the diagnosis was made at 6 weeks. It was based on carbohydrate tolerance tests and confirmed later by biopsy.

None of the children described by Burgess et al. (1964) had been followed up for more than a few months after diagnosis. Four, diagnosed between ages 13 months and 5 years, were seen again when aged between 11 and 16 years. Three could not be traced, 2 because they had left the country and one because he had been adopted.

Case 1 came to our notice because of school truancy and severe diarrhoea. He and his sister, Case 2, thought that sweet food made their symptoms worse but neither they nor their mother understood the implications of this nor knew their original diagnoses. Case 3 presented to the casualty department with episodes of diarrhoea and abdominal pain. Neither parents nor child had associated these symptoms with sugar ingestion. Cases 1 to 4 had repeat sucrose tolerance tests and Case 3 a repeat biopsy.

Five other children aged 6 weeks to 3 years at diagnosis were followed up until aged 3 to 9 years. Case 9 had a repeat sucrose tolerance test.

The symptoms of each child were recorded, a dietary history taken, and average daily sucrose and starch intake were calculated. As daily starch intake varied considerably, the figure given is only approximate. When distance from the hospital precluded a patient being seen, the parents completed a detailed questionnaire (Cases 6 and 8).

\section{Results}

All 9 children continued to have episodes of diarrhoea, often associated with abdominal pain, discomfort, or distension (Table). Most children had experienced some improvement after the first year of life and were able to eat small amounts of sucrose 